Anna Rędzioch-Korkuz (D)

University of Warsaw

annaredzioch@uw.edu.pl

\title{
Problems and Constraints in Translation: A Semiotic Perspective
}

\section{The problem of translation problems}

Limitations and impediments have recently become an even greater part of the translation process. On the way to producing a relevant target text, the translator will usually have to consider various options on the level of strategies and techniques. The much-quoted theory by Levý [1967], according to which translating should be seen as a pragmatic task that is connected with decision-making, since it resembles a game-theory procedure, may be even more true nowadays.

According to Piotrowska, the concept of translation problems seems interesting, since on the one hand it constitutes the axis on which translation theories revolve, but on the other hand the idea has not been researched from a systemic point of view [2007: 57]. Gutt [2010: 199] wrote that the analysis of translation problems and solutions is impossible and unnecessary, since "translation problems are as varied as the languages, informative intentions and contexts that give rise to them." Other scholars, thinking in a similar fashion, have not approached the concept as an academic phenomenon worth investigating due to its 
subjective nature [e.g. Nord 1988; Jääskeläinen 1993; cf. the opinion presented by Pym 2014]. The situation seems even worse, for the term appears to be absent from entries of widely available translation studies handbooks and encyclopedias [e.g. Shuttelworth and Cowie 1997; Delisle, Lee-Jahnke et al. 2006; Baker and Saldanha 2009]. Even if it does appear, it seems to be discussed from a narrow perspective, with scholars focusing on specific aspects of translation, such as interjections, dialects, idioms and proper names [e.g. Kittel, Frank et al. 2008].

However, The Handbook of Translation Studies edited by Gambier and van Doorslaer [2010] includes an entry written by Toury devoted to problems encountered in translation, based on findings put forward by the author in his previous papers and subsequently presented in a revised version of his seminal monograph [Toury 2012].

Toury [2010] suggests a conceptual three-fold perspective, emphasizing that the notion has an unclear terminological status. The most common way of perceiving the idea within the discourse on translation studies may be directly connected with translatability and appears in the context of the relation between the source and target text, i.e. when there is a need to translate the former into a particular target language or culture. It seems that this type of discourse can be traced back to the general problem of choosing the right strategy, creating a translation brief or determining the target locale and expectations.

Another understanding means particular instances of problems within an act of translation. In this context it seems that the postulate of the so-called assumed translation [Toury 1995/2012] is brought to life: the translated text serves as a collection of already made solutions and only by analysing this collection can one learn what has constituted problems, which in practice means comparing the translation with its original.

Toury mentions a third type, one which involves the process of translation: in this sense problems have a dynamic nature and may be observed "alongside the gradual unfolding" of the translation act [Toury 2010: 172]. He emphasizes that there is often a multiplicity of solutions which are considered along the way in the process. Indeed, this approach seems typical of studies based on the use of think-aloud methodology and conducted since the 1980s.

Translation problems have been one of the main focuses of such research, being viewed mainly from the process-oriented perspective. Krings [1986] provided a classification of features a translation problem 
should have, indicating for example the hesitation of the translator or consideration of various equivalents as characteristics signalling a problem within the translation process. Lörscher [1991] distinguished between strategic and non-strategic behaviour of the translator, saying that the latter is strictly connected with translation problems. Along the same line, Jääskeläinen and Trikkonen-Condit [1991] argued that a translation problem stands in opposition to the automatic stage of the process and affects its effectiveness and speed.

A similar point of view, one based on psycholinguistic prerequisites, was adopted by scholars investigating the problem of translator training. For instance, González Davies and Scott-Tennent [2005] argued that a translation problem may be defined from two perspectives: a local and a global one, depending on whether it refers to a certain element of the text or to the whole text, which means focusing on language errors within an equivalence-based framework. According to Kiraly [1995], it may be especially valuable for translation teachers, for it may help "understand the problems (linguistic, cultural, textual, comprehension, production) that occur during the progress of a translator's training," and "indicate the kinds of problem recognition, resolution, and evaluation strategies required" [1995: 111]. Mackenzie [1998: 2001] emphasizes the role of the student translator, understanding translation as a creative process aimed at solving problems.

According to Piotrowska [2007] the idea of translation problems will usually lead the discussion to another complex concept, that of the translation unit. All in all, the author summarized the discussion by providing quite a general and inexact perspective, saying that translation problems will be related to translation and language errors, language proficiency, untranslatability or the process of translation and its complex nature.

Such issues are not the only limitations to the translation process, since there are numerous sources of factors that can influence the whole translation environment in a restrictive way. Moreover, the discussion of translation problems does not seem to be rigid in terms of defining the object of the study, which makes it even more complicated, for the theory of translation studies has another notion at its disposal with an apparently similar semantic field, namely constraints. 


\section{Constraints in translation studies}

The notion of constraints has gained more prominence in translation studies, especially in the context of translation acts which involve a certain degree of multimodality. A more general perspective was discussed by among others Mayoral, Kelly et al. [1988], who offered a framework for constraints when translating films, comics, songs or poems and underlined the role of the presence of other communication systems and the change of the medium. Another typology of constraints was theorized by Toury [1995] and later on by Chesterman [1997]. The former introduced the idea of descriptive norms in translation, which he understood as observable instructions indicating what to do in a given situation and based on some accepted standards or regularities of behaviour.

Chesterman [1997] suggested a fairly opposing view. He perceived norms as prescriptive rules which limit the translator and are hence binding. In his classification Chesterman concentrated on both the process and the end product. Consequently, there are professional norms whose sources come from the behaviour accepted among professionals. The other group of norms, the expectancy norms, will be based on expectations of the target audience, certain cultural norms or conventions accepted within a given community.

The terminological dictionary edited by Delisle, Lee-Jahnke et al. [2006] provides an entry on constraints understood from a twofold perspective: on the one hand, constraints are defined as system-based rules which limit linguistic choices in a given context. The definition seems rather general, since it includes both grammatical and editing rules, for instance. On the other hand, constraints are said to be constituted by factors which are taken into consideration by the translator as a result of either conscious or unconscious action and which influence the processes of interpreting the source text and editing the target text. This approach seems to join two fundamentally disparate contexts: the subjective attitude of the translator along with his or her competence or idiolect, as well as the objective criterion of the broadly understood context of the translation process.

Apart from their visibility within a more global perspective, constraints appear as one of the key notions within the area of audiovisual translation: it seems to have started back in 1982, when Titford published an article on subtitling, which he regarded as "constrained". The 
issue became even more burning with the research results presented by d'Ydewalle, van Rensbergen et al. [1987], who arrived, for example, at the six-second rule, recurrent in the discussions on various restrictions in the subtitling process.

The subject has been discussed in more detail in subsequent years: Delabastita [1989] addressed the degree of reduction in subtitling. Along the same line, Gottlieb [1992] indicated quantitative and qualitative constraints in subtitling, pointing out the problems of temporal and spatial limitations and the image-word interrelationship. Díaz-Cintas and Remael [2007] and Pedersen [2011] concentrated on similar aspects, highlighting the problem of the medium change. Low [2002] and Mateo [2007] shifted attention to surtitling, arguing that the constraints are slightly different and are connected mainly with technical and temporal matters. Fodor [1969], Whitman-Linsen [1992] and Chaume [2012] indicated various types of synchronization as one of the major constraints in dubbing.

From this fairly brief introduction to the idea of problems and constraints in translation it may be possible to draw the following hypotheses. The idea of a translation problem seems to be connected either with a process-oriented perspective within a cognitive approach, or with a textbased perspective typical of a psycholinguistic or didactic approach. The notion centres mainly on the source text and the translator as an entity responsible for making decisions. In a traditional sense, then, a translation problem seems rather text-based and translator-dependent. The textbased nature stems from the fact that it refers to specific elements of a text connected with the idea of (un)translatability. Translation problems may then be conditioned variously, such as culturally, linguistically, textually or pragmatically.

On the other hand, it is the translator who determines if a given element is a translation problem or not. It follows, then, that the notion can be fairly subjective and dynamic, since it can depend on the translator and his or her competences, professional expertise and routine behaviour. Therefore, it seems almost impossible to provide a list of translation problems within a text, because the purely subjective nature of such choices could mean that one problem indicated by a given translator would constitute no problem for another. Hence, it may be only feasible to provide some general characteristics of the notion.

In this paper a translation problem is understood as a limitation connected with language-based aspects of the source text and presenting 
certain difficulties to the translator. Translation problems occur mainly because of two reasons: the first type of problem is related to structural differences between the source and target language, which requires employing techniques of compensation or paraphrase. The other type of problem is cultural contrast, which in practice means allusions, culturebound items, or humor. The solution to translation problems is usually determined by the translator, who acts within the process as an expert.

Constraints, on the other hand, are understood as extra-textual, objective and formal impediments, with sources in factors other than those linguistically related to the source text or culture [cf. constraints defined in González Davies 2004: 228]. In this fashion a constraint is seen as imposed on the translator from the outside, and thus is objective in nature. The actual choice of the strategy or tactics may therefore be independent of the translator, since constraints usually contain instructions. Moreover, non-compliance with such instructions may result in a translation that is not appropriate, adequate or accessible.

\subsection{A constraint-based model of translation}

In order to discuss translation problems and constraints it seems advisable to use a general model of translation and include basic translation entities and elements. A simple linear model highlights the directionality of the process and the comparative opposition between the source and target realities. It is assumed that both the source text and the target text function within cultural contexts and according to certain norms. The process of translation, on the other hand, takes place within precise pragmatic conditions, which draws attention not only to purely text- or language-related issues, but also to other factors, such as the time and place, pre-existing knowledge, and expectations.

However, translation semiosis seems far more complicated and multilayered. It occurs throughout the process within a broad framework of a communicative occurrence, which means that the meaning is a result of the concurrence of every agent, semiotic system, entity or constraint operating within that framework. Moving towards a more semiotics-based model of translation will mean not a linear but rather a space-oriented fashion of a nexus model.

Figure 1 presents a straightforward semiotics-based model of translation which complies with the Jakobsonian elements of communication. 
On the two ends of the translation semiosis continuum there are the two cultural backgrounds with their conventions, sign systems, norms and products: the source and target texts, respectively. In the broader perspective of semiotics, the word "text" shall be understood as a collection of semiotic systems (both verbal and non-verbal) organised in a specified manner according to a set of rules and meant to convey particular meanings [cf. Lotman 1981].

Figure 1. A semiotics-based model of translation (based on Jakobson 1960)

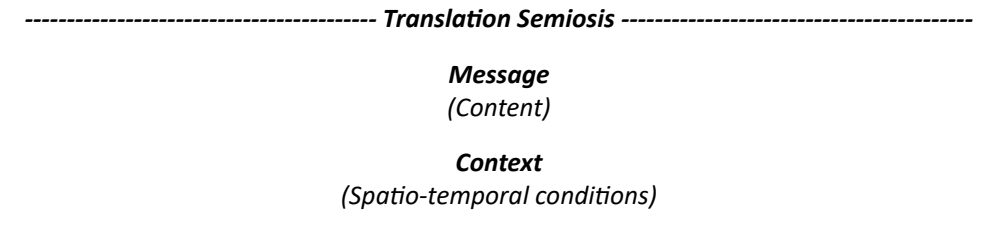

Source Culture --- Source Text Target Text --- Target Culture

(Addresser)

(Addressee)

\author{
Contact/Channel \\ (Medium) \\ Code \\ (Language/Semiotic Systems) \\ --- Translator ---
}

The umbrella names of addresser and addressee signal the fairly heterogeneous nature of the terms, with a number of persons/institutions determining to varying degrees the action of the translator [cf. Holz-Mänttäri 1984]. The actual make-up of the source or target entity depends on the translation modality or particular context. Apart from this, the model clearly underlines the conditions of the translation process, not only the text-related ones (under the heading "Message"), but also others, including pragmatic, technical, and semiotic ones (under the headings "Context", "Contact/Channel" and "Code", respectively).

The starting point of the translation semiosis seems to be the existence of the source text and the need or intention to translate it into the target language, with the predominant goal of producing a relation of resemblance between the two texts, which, as argued by Lewandowska-Tomaszczyk 
[2017: 133-134], will consist in "a re-conceptualization of an original message $[\ldots]$ to form a hybrid, blended entity" (italics in original). The translator acts as a language expert, an initial addressee and secondary addresser, reconciling all skopoi existing within the translation environment. The Message is the informative content the translator has to work on: in this paper it is understood as the textual (in a linguistic sense) layer of the source text, which should be translated, but which can also be manipulated, edited or condensed because of other elements of the process. In this sense the translator retains his or her ontological role of a language specialist.

It follows, then, that every element is connected with specific aspects that should be considered while translating. The translator should have some means or instructions she or he can resort to, especially when the whole process seems burdened with impediments of various origins. The instructions may come from the analysis of those impediments, which may be seen as either translation problems or constraints depending on their nature and immediate source. Analysing the model from Figure 1 in this fashion may lead to a working typology of constraints linked to a particular entity within the model:

Figure 2. A constraint-based model of translation

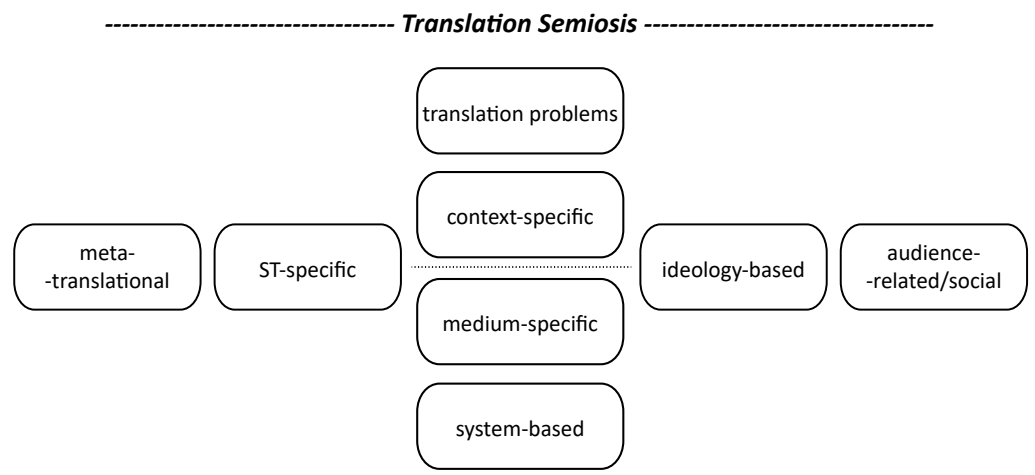

Translation problems are connected with the Message or the content, since the informative content is the linguistic material the translator has to deal with as a language specialist. Structural or culture-related problems 
manifested in the verbal layer are approached from a fairly subjective point of view, meaning that it is the translator who determines the final choice of procedures. The choice has to comply with more general and objective constraints. However, it is believed that (at least in an ideal translation environment) the translator should be competent enough to make the best choice in accordance with other formal requirements.

The source side of the model is connected with meta-translational and ST-specific constraints. The first group pertains to overall conditions of the process, e.g. translation briefs, or the individual expectations of the commissioner or original author. As a general rule, it comes down to choosing the right strategy, such as domesticating or foreignizing. STspecific constraints, on the other hand, may concern the semiotic make-up of the source text: the problem of text typology or intersemiotic translation can become predominant in this case. In practice, it can mean exercising the idea of optimal relevance and redundancy to produce an adequate target text.

Context-specific constraints are rooted in the temporal conditions of the translation semiosis or the relation between the source and target locales. It may be related to various problems like the question of the time-span or regional language varieties. It creates the necessity to adjust the text mainly due to stylistics. Today, context-specific constraints can be observed in localizing software, games, websites or other multimedia content, when the target product needs to be translated and adapted for distinct markets or audiences.

Problems arising from quantitative matters or issues related to the graphics of the source text may be grouped under the heading of mediumspecific constraints, which compel the translator to analyse the source text in a wider context and resort to, for instance, condensing or simplifying the original. System-based constraints may, on the other hand, be linked to the technical profile or limitations of systems used to convey the translated message, which, again, may require certain changes to the layout, text distribution or density.

On the part of the target text and audience there are formal restrictions imposed by authorities or arising from norms, conventions or regulations. The target text may be perceived through the prism of ideology-based constraints: a specific point of view or political or religious associations can have a considerable impact on decision-making, working as a filter removing or altering inappropriate content. 
Characteristics of the target audience (both users and receivers) will usually produce a strong effect on the translation process and its outcome. Audience-related constraints are limited to specific features of the target group, including their sex, age, prior knowledge and intentions. Social constraints are more global, pertaining to normative expectations of the target culture, language acceptability or long-established tradition, which may, for instance, call for cultural equivalents or recognized translation.

The translator may be regarded as yet another element influencing the final shape of the target text and the whole process. But can she or he be considered a constraint? Maybe to some extent, since the competence or formal education of the translator as well as his or her mood may have an impact on the global strategy or tactics while approaching a particular translation problem [cf. Waliński 2016]. This may be illustrated with the case of swearwords and their translation: in addition to formal regulations or requirements of other agents, all of which may come under the umbrella term of constraints, the translator may be driven by a sense of self-correctness, narrowing down the number of possibilities.

The boundaries between constraints are not clear-cut: for example, medium-specific and ST-specific constraints may influence the final make-up of the target text, since they may require condensation; ideology-based constraints may be parallel to meta-translational constraints in terms of the overriding strategy, with the commissioner having in mind a particular shape of the target text and profile of the target audience.

Even though the words "constraint" and "problem" have negative connotations, it may be said that knowledge and analysis of those constraining agents may prove helpful in the everyday practice or the didactics of translation. Operating within constraints can guide the translator towards logical solutions: as noticed by Toury [1995], norms, which he perceived as constraints, "always imply sanctions - actual or potential, negative as well as positive." The negative aspect seems quite clear and etymologically grounded in the usage of both words. The positive aspect will consist in making the decision-process easier and more effective by limiting the number of potential decisions. As a consequence, adopting only viable or reasonable solutions is more likely to produce an appropriate target text that would fit the requirements of the translation process. 


\section{Constraints in practice}

A proper understanding of constraints may have a wide range of applications: not only can it become of invaluable help in everyday translation practice, but it can also be useful from the point of view of didactics or translation assessment. This hypothesis may be illustrated by the following examples coming from various contexts.

The first case is an example of opera surtitling, which is beset with constraining factors, making the task demanding and time-consuming. The surtitler will usually work with a translated libretto, so potential translation problems may be dealt with by the translator at a prior stage of the process. As a rule, the task involves producing digestible sense-blocks in a relevant and audience-friendly manner that matches the actual staging.

The example was taken from Act Two from Samson and Delilah by Camille Saint-Saëns staged in Wrocław. It presents an extract from the aria Mon coeur s'ouvre a ta voix, sung by the main character (Table 1). The textual source was a faithful translation of the French libretto by Jolanta Małecka-Juchymiuk, which was projected in a barely unaltered form. The surtitles seem to violate certain AVT rules, e.g. the appropriate number of characters, simplified syntax or no unnecessary repetitions. Moreover, they do not comply with the instructions imposed by theoretical constraints operating in this context.

Apart from the obvious context-specific constraints, which in this case mean a live performance with unpredictable audience reactions or music determining the exposure times, it seems necessary to consider ST-specific constraints (a multimodal and polysemiotic construct; for more insights see e.g. Rędzioch-Korkuz 2016), medium-specific constraints (changing the medium, which calls for condensing the original), audience-related or social constraints (the audience as a non-homogenous group, which means different reading speeds, knowledge, or prior experience) as well as system-based constraints (e.g. different projecting systems or illegible characters). Unless meta-translational constraints impose a rigid pattern of behaviour (e.g. transferring the libretto in an unaltered form), the surtitler may receive helpful instructions based on these impediments and create a relevant, tailor-made and redundancy-free product (the right column in Table 1).

As shown, the suggested surtitles lack unnecessary elements (in bold) or render certain information in a different way. They do not contain 
repetitions, possessive adjectives, exclamations or prepositional phrases. The syntax and punctuation are simplified, which is in line with general guidelines of AVT.

Table 1. Opera surtitling

\begin{tabular}{|l|l|}
\hline Original surtitles & Suggested surtitles \\
\hline $\begin{array}{l}\text { Tak jak widać kłosy zbóż falujące na } \\
\text { lekkim wietrzyku - } \\
\text { to w ten sposób drży moje serce!... }\end{array}$ & $\begin{array}{l}\text { Jak kłosy zbóż falujące na wietrze } \\
\text { drży moje serce, }\end{array}$ \\
\hline $\begin{array}{l}\text { Serce gotowe do pocieszenia się } \\
\text { twoim głosem, } \\
\text { który tak jest mi drogi! }\end{array}$ & $\begin{array}{l}\text { czekające na twój głos } \\
\text { tak bardzo mi drogi! }\end{array}$ \\
\hline $\begin{array}{l}\text { Strzała jest mniej szybka do zadania } \\
\text { śmierci, } \\
\text { aniżeli twoja kochanka jest gotowa } \\
\text { wpaść w twoje ramiona! }\end{array}$ & $\begin{array}{l}\text { Strzała nie zada śmierci tak szybko, } \\
\text { jak kochanka wpadnie w twe ramiona. }\end{array}$ \\
\hline $\begin{array}{l}\text { :Ach, odpowiedz na moją czułość } \\
\text { wlej mi upojenie } \\
\text { odpowiedz na moją czułość:| }\end{array}$ & $\begin{array}{l}\text { |:Odpowiedz na moją czułośćc } \\
\text { i ześlij upojenie.:| }\end{array}$ \\
\hline
\end{tabular}

In this case, constraints are helpful in two ways: they offer a proper framework of analysis, indicating points that should be considered and providing useful instructions. Additionally, this framework seems to be fairly general and dynamic, which means that it can offer slightly different solutions every time, keeping them within restrictions typical of this modality. This, in turn, may guarantee sustaining standards and developing good translation (surtitling) practice.

The analysis of constraints may be beneficial for student translators as well, especially at the beginner level, since it may help understand translation from a broader perspective and see the dynamic nature of fundamental concepts. The first case may be exemplified by a translation task presented to a group of BA students of translation (Table 2): 
Table 2. Interlingual translation

TASK 1: Translate the following dialogue into Polish.

(CONTEXT: A short dialogue between two creatures: Mother Goose wants Grimm not to reveal a secret about the missing cat, Attila.)

"Grimm, Attila is missing. I haven't seen him since last night. But keep it secret, I don't want anyone to be alarmed."

"Don't worry. I won't let the cat out of the bag."

At first, the students were provided with no further context, except for the information in brackets. The potential difficulty found in the text was the translation problem in the last sentence, that of the idiomatic phrase. The problem was solved quite easily (provided it was identified), with the students arriving at various versions of the expression. In the next step, they were presented with the actual context of the dialogue as it originally appeared in the comic strip Mother Goose and Grimm created by Mike Peters (Fig. 3).

Figure 3. The original context
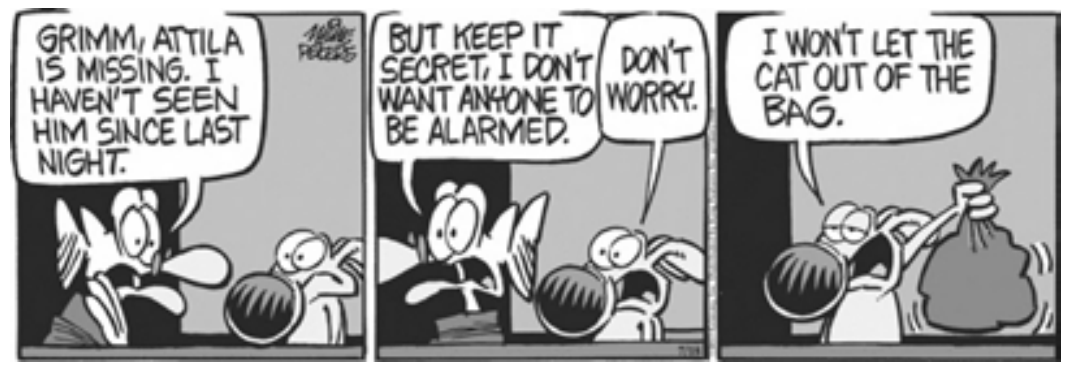

Retrieved from http://www.thecomicstrips.com/store/add.php?iid=99089-10.02.2020

The students reacted rather dramatically, saying that it was impossible to match their translations with the image, stay faithful to the original and retain the comic effect. However, the subsequent analysis of constraints cast fresh light on the task: the ST-specific constraint helped to shift attention to the final panel and the image-word relation of complementarity, whereas the medium-specific constraint helped to exclude lines that 
would not fit the allocated space. The meta-translational constraint reminded the students to retain the humorous effect and the brevity of the strip. In the end, the constraints facilitated the whole process and justified the necessity to alter the original to a considerable degree in the second panel and shape it in a way that would fit the third panel.

The final point also turned out to be of help in a different task, which involved a comparative analysis of song translation. In this case the students were asked to analyse a translation of the song Let it Go by Kristen Anderson-Lopez and Robert Lopez from Disney's box-office hit Frozen. The Polish singable translation was provided by Michał Wojnarowski and at points, as a matter of fact, it violates the concept of equivalence (Table 3). It often happens that at the beginning of a course student translators are firmly rooted in translation theory with a strong sense of equivalence or faithfulness, which in this case resulted in a negative evaluation of the translation.

Table 3. Singable translation

\begin{tabular}{|c|c|}
\hline Source text & Target text \\
\hline Let it go, let it go & Mam tę moc! Mam tę moc! \\
\hline Can't hold it back anymore & Rozpalę to co się tli. \\
\hline Let it go, let it go & Mam tę moc! Mam tę moc! \\
\hline Turn away and slam the door & Wyjdę i zatrzasnę drzwi! \\
\hline I don't care & Wszystkim wbrew, \\
\hline what they're going to say & na ten gest mnie stać! \\
\hline Let the storm rage on & Co tam burzy gniew? \\
\hline The cold never bothered me anyway & Od lat coś w objęcia chłodu mnie pcha. \\
\hline
\end{tabular}

The analysis of constraints made it possible to see far beyond the simple interlinguistic translation: the ST-specific constraint made it clear that the make-up of the source text involves both verbal and non-verbal (acoustic) signs, which form a harmonious whole. The medium-specific constraint highlighted the medium of communication: the source text is a song; hence the most significant factor seems the idea of its "singability", which necessitates using certain vowels or a certain number of syllables. In addition, the context-specific constraint provides another piece of information, that the song is a part of a greater whole and should form 
a matching and coherent element. Having discussed the constraints, the students were able to justify translational choices and saw key notions of translation studies as dynamic and broad concepts.

The examples presented above constitute just a small-scale representation of aspects connected with translation and may not reflect all constraints found in real contexts. However, it is hoped that they may prove the potential of a constraint-based model of translation for both professionals and student translators.

\section{Conclusions}

Translation is without doubt a demanding task, irrespective of the actual type of translation activity. Eco noted that "every sensible and rigorous theory of language shows that a perfect translation is an impossible dream" [Eco 2001: ix]. However, he admitted that people do and will translate regardless of this inevitable impossibility of reaching a perfect solution. Fortunately, there are a few instructions, such as the "minimax" strategy, which means opting for solutions not reflecting the original meaning but "more or less, expressive meaning and stylistic values, though it is probable that, after hours of experimenting and rewriting, a better solution might be found" [Levý 1967: 2]. This ongoing nature of the translation process may be of little consolation, but a proper approach may remedy this problem.

A semiotics-based perspective may help one to see a broader context, with the main focus shifted from language- and text-focused aspects of the source text. It provides a more systemic approach, which makes the analysis of tasks well-ordered and easier: it consists in analysing the task step by step and concentrating on each level or element: still, the framework seems general enough to include different activities and indicate potential constraints.

The knowledge of constraints may, in turn, help the translator limit the number of solutions and hopefully rule out the least appropriate ones. Thus, it may lead to choosing the most adequate strategy or technique. What is more, a proper analysis of constraints may offer a fresh attitude towards assessing translations and translators, since it can rationalize various choices. And finally, the awareness of constraints may contribute to developing and maintaining certain standards of specific translation 
practice, since they seem to be typical and universal within a certain type of translation.

\section{References}

Baker, M., Saldanha, G. (2009), Routledge Encyclopedia of Translation Studies, $2^{\text {nd }}$ Edition, Routledge, London-New York, https://doi. org/10.4324/9780203872062.

Chaume, F. (2012), Audiovisual Translation: Dubbing, St Jerome, Manchester. Chesterman, A. (1997), Memes of Translation: The Spread of Ideas in Translation Theory, John Benjamins, Amsterdam-Philadelphia, https://doi.org/10.1075/ bt1.22.

Delabastita, D. (1989), "Translation and Mass Communication: Film and TV Translation as Evidence of Cultural Dynamics", Babel, 35(4), pp. 193-218, https://doi.org/10.1075/babel.35.4.02del.

Delisle, J., Lee-Jahnke, H., Cormier, M. C. (eds.) (2006), Terminologia tlumaczenia, (translated by T. Tomaszkiewicz), Wydawnictwo Naukowe UAM, Poznań.

Díaz-Cintas, J., Remael, A. (2007), Audiovisual Translation: Subtitling, St Jerome, Manchester-Kinderhook.

d'Ydewalle, G., van Rensbergen, J., Pollet, J. (1987), "Reading a Message when the Same Message is Available Auditorily in Another Language: The Case of Subtitling”, in: J. K. O’Regan, A. Lévy-Schoen (eds.), Eye Movements: From Psychology to Cognition, Elsevier Science, Amsterdam, pp. 313-321, https:// doi.org/10.1016/B978-0-444-70113-8.50047-3.

Eco, U. (2001), Experiences in Translation, (Translated by A. McEwen), University of Toronto Press, Toronto-Buffalo-London.

Fodor, I. (1969), "Linguistic and Psychological Problems of Film Synchronisation", Acta Linguistica Scientiarum Hungaricae, 19, pp. 69-106 and 379-394.

Gambier, Y., van Doorslaer, L. (eds.) (2010), Handbook of Translation Studies, Vol. 2, John Benjamins, Amsterdam-Philadelphia, https://doi.org/10.1075/ hts.1.

Gonzáles Davies, M. (2004), Multiple Voices in the Translation Classroom: Activities, Tasks and Projects, John Benjamins, Amsterdam-Philadelphia, https://doi.org/10.1075/btl.54.

Gonzáles Davies, M., Scott-Tennent, C. (2005), “A Problem-solving and Studentcentred Approach to the Translation of Cultural References", Meta, 50-51, pp. 160-179, https://doi.org/10.7202/010666ar. 
Gottlieb, H. (1992), "Subtitling - A New University Discipline", in: C. Dollerup, A. Loddegaard (eds.), Teaching Translation and Interpreting, John Benjamins, Amsterdam, pp. 161-170, https://doi.org/10.1075/z.56.26got.

Gutt, E.-A. (2010), "Relevance: A Key to Quality Assessment in Translation", in: B. Lewandowska-Tomaszczyk, M. Thelen (eds.), Meaning in Translation, Peter Lang, Frankfurt am Main, pp. 267-282.

Holz-Mänttäri, J. (1984), Translatorisches Handeln - Theorie und Methode, Suomalainen Tiedeakatemia, Helsinki.

Jakobson, R. (1960), "Closing Statements: Linguistics and Poetics", in: T.A. Sebeok (ed.), Style in Language, MIT Press, Cambridge Mass., pp. 350-377.

Jääskeläinen, R. (1993), "Investigating Translation Strategies”, in: S. Trikkonen-Condit, J. Laffling (eds.), Recent Trends in Empirical Translation Research (Studies in Language), 28, University of Joensuu, Joensuu, pp. 99-120.

Jääskeläinen, R., Trikkonen-Condit, S. (1991), "Automatised Processes in Professional vs. Non-professional Translation: A Think-aloud Protocol Study", in: S. Trikkonen-Condit (ed.) Empirical Research in Translation and Intercultural Studies. Selected Papers of the TRANSIF Seminar, Savonlinna, 1988, Gunter Narr, Tübingen, pp. 89-110.

Kiraly, D. C. (1995), Pathways to Translation. Pedagogy and Process, Kent State University Press, Kent-Ohio-London.

Kittel, H., Frank, A. P., Greiner, N., Hermans, T., Koller, W., Lambert, J., Paul, F. (eds.) (2008), Übersetzung - Translation - Traduction, Vol. 1, De Gruyter Mouton, Berlin-Boston, https://doi.org/10.1515/9783110171457.

Krings, H. P. (1986), "Translation Problems and Translation Strategies of Advanced German Learners of French", in: J. House, S. Blum-Kulka (eds.), Interlingual and Intercultural Communication: Discourse and Cognition in Translation and Second Language Acquisition Studies, Gunter Narr, Tübingen, pp. 263-275.

Levý, J. (1967), "Translation as a Decision Process", in: To Honour Roman Jakobson: Essays on the Occasion of his $70^{\text {th }}$ Birthday, Vol. 2, Mouton, The Hague, pp. 1171-1182, https://doi.org/10.1515/9783111349121-031.

Lewandowska-Tomaszczyk, B. (2017), "Partial Perception and Approximate Understanding", Research in Language, 15(2), pp. 129-152, https://doi. org/10.1515/rela-2017-0009.

Lotman, J. (1981), Kunst als Sprache. Untersuchungen zum Zeichencharakter von Literatur und Kunst, (Translated by M. Dewey et al.), Philipp Reclam jun., Leipzig. 
Low, P. (2002), "Surtitles for Opera: A Specialised Translating Task", Babel, 48(2), pp. 97-110, https://doi.org/10.1075/babel.48.2.01low.

Lörscher, W. (1991), Translation Performance, Translation Process, and Translation Strategies. A Psycholinguistic Investigation, Gunter Narr, Tübingen.

Mackenzie, R. (1998), "Creative Problem-solving and Translator Training”, in: A. Beylard-Ozeroff, J. Králová, B. Moser-Mercer (eds.), Translators' Strategies and Creativity. Selected Papers from the $9^{\text {th }}$ International Conference on Translation and Interpreting, Prague, September 1995, John Benjamins, Amsterdam-Philadelphia, pp. 201-205, https://doi.org/10.1075/btl.27.27mac.

Mateo, M. (2007), "Reception, Text and Context in the Study of Opera Surtitles", in: Y. Gambier, M. Schlesinger and R. Stolze (eds.), Doubts and Directions in Translation Studies, John Benjamins, Amsterdam-Philadelphia, pp. 169-182, https://doi.org/10.1075/btl.72.18mat.

Mayoral, R., Kelly, D., Gallardo, N. (1988), “Concept of Constrained Translation. Non-linguistic Perspective on Translation", Meta, 33(3), pp. 356-367, https://doi.org/10.7202/003608ar.

Nord, Ch. (1988), Textanalyse und Übersetzen, Julius Groos, Heidelberg.

Pedersen, J. (2011), Subtitling Norms for Television: An Exploration Focusing on Extralinguistic Cultural References, John Benjamins, Amsterdam-Philadelphia, https://doi.org/10.1075/btl.98.

Piotrowska, M. (2007), Proces decyzyjny tlumacza, podstawy metodologii nauczania przektadu pisemnego, Wydawnictwo Naukowe Akademii Pedagogicznej, Kraków.

Pym, A. (2014), Exploring Translation Theories, $2^{\text {nd }}$ Edition, Routledge, New York.

Rędzioch-Korkuz, A. (2016), Opera Surtitling as a Special Case of Audiovisual Translation. Towards a Semiotic and Translation Based Framework for Opera Surtitling, Peter Lang, Frankfurt am Main, https://doi. org/10.3726/978-3-653-06943-3.

Shuttleworth, M., Cowie, M. (1997), Dictionary of Translation Studies, St Jerome Publishing, Manchester.

Titford, C. (1982), "Sub-titling: Constrained Translation", Lebende Sprachen, 27(3), pp. 113-116.

Toury, G. (1995), Descriptive Translation Studies and Beyond, John Benjamins, Amsterdam-Philadelphia, https://doi.org/10.1075/btl.4.

Toury, G. (2010), “Translation Problem”, in: Y. Gambier, L. van Doorslaer (eds.), Handbook of Translation Studies, Vol. 2, John Benjamins, Amsterdam-Philadelphia, pp. 169-174. 
Toury, G. (2012), Descriptive Translation Studies - and Beyond. Revised Edition, John Benjamins, Amsterdam-Philadelphia, https://doi.org/10.1075/btl.100. Waliński, J. T. (2016), "How to Sneeze off Papers from the Desk in Polish Translation: Re-conceptualization and Approximation at Work", in: Ł. Bogucki, B. Lewandowska-Tomaszczyk, M. Thelen (eds.), Translation and Meaning. New Series, Vol. 2, Peter Lang, Frankfurt am Main, pp. 85-105.

Whitman-Linsen, C. (1992), Through the Dubbing Glass. The Synchronization of American Motion Pictures into German, French and Spanish, Peter Lang, Frankfurt am Main.

\begin{abstract}
Constraints are an integral part of translation: in addition to purely linguistic, social and cultural aspects, professionals often have to deal with ideological, technical and ethical problems, which unlocks the potential of semiotics for translation studies. The article presents a working typology of potential constraints operating in translation. It highlights the distinction between translation problems and constraints, with the latter understood as any potential and objective factor which limits the performance of translators, forcing them to apply problem-solving tactics to produce a relevant target text. It is argued that even though the terms "constraint" and "problem" have negative connotations, the knowledge of potential impediments can often prove helpful, since it can facilitate translation by restricting possibilities or justify chosen techniques. The argumentation is supported by examples of constraints, their sources, and accepted practice.
\end{abstract}

Keywords: translation, semiotics, problems, constraints, model 